\title{
Aberrant methylation of microRNA-193b in human Barrett's esophagus and esophageal adenocarcinoma
}

\author{
LIN LÜ ${ }^{1}$, TIANYU LIU ${ }^{2}$, JIAN GAO ${ }^{1}$, HANQING ZENG $^{3}$, JIA CHEN $^{1}$, XILING GU $^{4}$ and ZHECHUAN MEI ${ }^{1}$ \\ ${ }^{1}$ Department of Gastroenterology, The Second Affiliated Hospital, Chongqing Medical University, Chongqing 400010; \\ ${ }^{2}$ Department of Gastroenterology, Suining Central Hospital, Suining, Sichuan 629000; \\ Departments of ${ }^{3}$ Hematology and ${ }^{4}$ Pathology, The Second Affiliated Hospital, \\ Chongqing Medical University, Chongqing 400010, P.R. China
}

Received June 9, 2015; Accepted March 4, 2016

DOI: $10.3892 / \mathrm{mmr} .2016 .5225$

\begin{abstract}
The present study aimed to investigate the expression and regulation of microRNA-193b (miR-193b) in tissues and cells from esophageal cancer and Barrett's esophagus (BE). Surgical biopsies of esophageal lesions and adjacent normal tissues were obtained, and the miR-193b expression and promoter methylation status were examined. Human BE and esophageal cancer cells were analyzed for miR-193b expression and promoter methylation, with or without treatment with the hypomethylating agent 5-azacytidine. Immunohistochemistry was performed to determine the expression and distribution of Kirsten rat sarcoma viral oncogene homolog (K-Ras), a target of miR-193b. miR-193b expression was significantly downregulated in $\mathrm{BE}$ and esophageal cancer tissues compared with corresponding normal tissues. The miR-193b level was significantly reduced in esophageal cancer compared with BE tissue. 5-Azacytidine treatment resulted in a significant upregulation of miR-193b in BE and esophageal cancer cells. Methylation-specific polymerase chain reaction analysis and bisulfite pyrosequencing confirmed hypermethylation of miR-193b promoter regions in esophageal cancer and $\mathrm{BE}$ cells, whereas hypermethylation was not observed in normal esophageal squamous epithelial cells. The methylation rate in $\mathrm{BE}$ and esophageal cancer tissues was significantly increased compared with the adjacent normal esophageal tissues. BE and esophageal cancer tissues exhibited increased K-Ras protein expression levels compared with the adjacent normal tissues. To the best of our knowledge, this is the first report describing DNA methylation-mediated silencing of miR-193b in esophageal cancer and BE tissues.
\end{abstract}

Correspondence to: Professor Zhechuan Mei, Department of Gastroenterology, The Second Affiliated Hospital, Chongqing Medical University, 76 Linjiang Road, Chongqing 400010, P.R. China E-mail: meizhechuan@21cn.com

Key words: carcinogenesis, epigenetic modification, esophageal cancer, microRNA, tumor suppressor gene

\section{Introduction}

Esophageal cancer is the seventh most common type of cancer and sixth leading cause of cancer-associated mortality worldwide (1). There are 2 major histological types of esophageal cancer, squamous cell carcinoma (SCC) and adenocarcinoma. SSC is the most prevalent esophageal cancer worldwide, particularly in developing countries (2). However, the incidence of esophageal adenocarcinoma (EAC) has dramatically increased in the past 40 years (2). From 1975 to 2004, the incidence of EAC among Caucasian American males increased by $>460 \%$ and over the same time period, the incidence among Caucasian American females increased by $335 \%$ (3). Barrett's esophagus (BE) is a metaplastic lesion of the distal esophagus characterized by the replacement of the normal stratified squamous epithelium by a metaplastic, columnar-lined epithelium. Untreated BE can develop dysplasia and progress to adenocarcinoma. Thus, BE is regarded as the precursor to EAC. Patients with $\mathrm{BE}$ have a 30 - to 60-fold increased risk of developing EAC compared with the general population (4-7).

MicroRNAs (miRNAs) are a class of small, non-coding regulatory RNAs of 22 nucleotides in length, that are important in various aspects of biology (8). Typically, miRNAs negatively regulate gene expression by binding to the 3'-untranslated region (UTR) of target mRNAs, leading to mRNA degradation and/or translational repression (9). Dysregulation of miRNAs is observed in various types of human cancer, including esophageal cancer $(10,11)$. A large number of miRNAs have been identified to act as oncogenes or tumor suppressor genes, contributing to cancer development and progression (12). Compelling evidence suggests that miRNAs may be novel molecular biomarkers for cancer detection and targeted therapies (13).

DNA methylation is a crucial epigenetic mechanism associated with the dysregulation of miRNAs in cancer (14). Several tumor-suppressing miRNAs have been identified to be epigenetically silenced in esophageal cancer. miR-375 expression is downregulated by hypermethylation of its promoter in esophageal cancer compared with adjacent non-tumorous tissues (15). Additionally, miR-34a methylation is associated with its downregulation in esophageal cancer (16). miR-193b 
functions as a tumor suppressor in multiple malignancies, including melanoma (17), prostate (18), and breast (19) cancer. Downregulation of miR-193b via DNA methylation has been previously observed in prostate cancer (18). Despite these findings, the importance of miR-193b expression and regulation in the pathogenesis of esophageal cancer remains unclear.

Therefore, the present study aimed to investigate the expression and epigenetic regulation of miR-193b in esophageal cancer and patients with BE.

\section{Materials and methods}

Tissue samples. A total of 22 patients with esophageal cancer (16 males and 6 females) and 14 with BE (4 males and 10 females) were enrolled in the current study. The patients were treated at the Second Affiliated Hospital, Chongqing Medical University (Chongqing, China). The mean age \pm standard deviation of patients with esophageal cancer and BE was $65 \pm 9$ and $45 \pm 10$ years, respectively. Definitive histological diagnosis of esophageal cancer or BE was performed for each patient. Surgical biopsies of esophageal lesions and adjacent normal tissues ( $>5 \mathrm{~cm}$ from the tumor margin) were obtained from all the patients with informed consent. One part of the tissue samples was immediately snap-frozen in liquid nitrogen and stored at $-80^{\circ} \mathrm{C}$ prior to DNA or RNA extraction. The remaining samples were fixed in $4 \%$ formaldehyde (Sigma-Aldrich, St. Louis, MO, USA) overnight, embedded in paraffin, sectioned and then stained with hematoxylin and eosin (Sigma-Aldrich). The study was approved by the Ethics Committee of Chongqing Medical University (approval number, CMU-2012-024).

Cell culture and demethylation treatment. Human BE cell lines (B-T, B-T9 and B-T10), esophageal cancer (EC) cell lines (EC109, TE-10 and SEG-1), and normal esophageal squamous epithelial cells were obtained from the American Type Culture Collection (Manassas, VA, USA). The cells were cultured in RPMI 1640 medium (Invitrogen; Thermo Fisher Scientific, Inc.) supplemented with $10 \%$ fetal bovine serum (FBS; Invitrogen; Thermo Fisher Scientific, Inc., Waltham, MA, USA), $100 \mathrm{U} / \mathrm{ml}$ penicillin and $100 \mu \mathrm{g} / \mathrm{ml}$ streptomycin (Invitrogen; Thermo Fisher Scientific, Inc.) in a humidified environment at $37^{\circ} \mathrm{C}$ with a $5 \% \quad \mathrm{CO}_{2}$ atmosphere. For demethylation studies, cells in 6 -well plates $\left(5 \times 10^{6}\right.$ cells/well $)$ were serum-starved for $8 \mathrm{~h}$ and subsequently exposed to 5-azacytidine (10 $\mu \mathrm{M}$; Sigma-Aldrich) in the presence of $10 \%$ FBS for a further $72 \mathrm{~h}$. Cellular DNA and RNA were isolated and subjected to gene expression and methylation analysis, as described below.

Reverse transcription-quantitative polymerase chain reaction (RT-qPCR) analysis of miR-193b expression. Total RNA was isolated from the BC and EC cells using the miRNA Isolation kit (Takara Biotechnology Co., Ltd., Dalian, China) and treaed with DNase I (Takara Biotechnology Co., Ltd.). The level of mature human miR-193b (5'-AACUGGCCC UCAAAGUCCCGCU-3') was measured using the TaqMan MicroRNA Assay (Applied Biosystems; Thermo Fisher Scientific, Inc., Waltham, MA, USA) according to the manufacturer's protocol. Briefly, RT was performed with an
miRNA-specific stem-loop primer (cat. no A25576; Applied Biosystems; Thermo Fisher Scientific, Inc.) and the reaction was performed at $16^{\circ} \mathrm{C}$ for $30 \mathrm{~min}$, followed by $42^{\circ} \mathrm{C}$ for $30 \mathrm{~min}$ and $85^{\circ} \mathrm{C}$ for $5 \mathrm{~min}$. qPCR was performed using $0.5 \mu \mathrm{g}$ of cDNA and a TaqMan MicroRNA Assay kit (Applied Biosystems; Thermo Fisher Scientific, Inc.) using a 7900HT Real-Time PCR system (Applied Biosystems; Thermo Fisher Scientific, Inc.). The cycling conditions were as follows: $95^{\circ} \mathrm{C}$ for $2 \mathrm{~min}$, followed by 40 cycles of $95^{\circ} \mathrm{C}$ for $10 \mathrm{~s}$ and $60^{\circ} \mathrm{C}$ for $30 \mathrm{~s}$. The primer sequences were as follows: miR193b, forward 5'-CTGACTCAGCTCGTTTGTGATG-3' and reverse 5'-AGGTAAACTGGCCCTCAAAGT-3'; U6 forward, 5'-CTCGCTTCGGCAGCACA-3' and reverse, 5'-AACGCT TCACGAATTTGCGT-3'. All reactions were performed in triplicate. The relative miR-193b levels were normalized to the level of U6 small nuclear RNA, calculated using the comparative quantification cycle $(\Delta \Delta \mathrm{Cq})$ method (20).

DNA methylation analysis. For determination of the methylation status of the promoter region of miR-193b gene, genomic DNA was extracted from the cells using the Genomic DNA Purification kit (Takara Biotechnology Co., Ltd.) and treated with sodium bisulfite using the EZ DNA Methylation-Gold kit (Zymo Research Corporation, Irvine, CA, USA). Methylation-specific PCR (MSP) was performed with the Taq Hot Start Version (Takara Biotechnology Co., Ltd.). The primers specific for methylated and unmethylated sequences are as follows: Methylation-specific sense primer, 5'-TTT TAGGTTTGTTTGTTGGGC-3'; unmethylation-specific sense primer, 5'-GTTTTTAGGTTTGTTTGTTGGGT-3'; and antisense primer, 5'-TCAAAAAATAAATCCCCATTCAC-3'. An enzymatically methylated DNA was included as a positive control, and unmethylated lymphocyte DNA as a negative control. PCR products were separated on $2 \%$ agarose gel and stained with ethidium bromide (Takara Biotechnology Co., Ltd.).

miR-193b methylation status was also measured by bisulfite pyrosequencing, as described previously (21). In brief, genomic DNA was extracted and subjected to bisulfite conversion. PCR amplification of the region located $\sim 2,000$ bp upstream from the transcription site of miR-193b was performed using the following primers: F 5'-TTTATT TAGCTGGAGATGGGGTG-3'; and R 5'-ACCACAGCC TCCAAAAGCCTC-3'. The region analyzed by bisulfite pyrosequencing included $19 \mathrm{CpG}$ sites from the miR-193b promoter. PCR products were purified and pyrosequencing was performed using a PyroMark Gold reagent kit (Qiagen $\mathrm{GmbH}$, Hilden, Germany) according to the manufacturer's protocol.

Immunohistochemistry. Paraffin sections (4- $\mu$ m thick) were deparaffinized with xylene (Sigma-Aldrich), rehydrated in a graded ethanol series and heated for $5 \mathrm{~min}$ at $100^{\circ} \mathrm{C}$ in the presence of $10 \mathrm{mM}$ sodium citrate ( $\mathrm{pH} \mathrm{6.0;}$; Sigma-Aldrich) to retrieve antigen. Following blocking with normal goat serum for $30 \mathrm{~min}$, sections were incubated with a polyclonal rabbit anti-human Kirsten rat sarcoma viral oncogene homolog (K-ras) antibody (1:1,000; ab84573; Abcam, Cambridge, UK) overnight at $4^{\circ} \mathrm{C}$. Subsequently, section were washed with phosphate-buffered saline (pH 7.4; Thermo Fisher Scientific, 
Inc.) and incubated with a biotin-labeled goat anti-mouse antibody (ab6788; Abcam) and horseradish peroxidase-conjugated streptavidin (Sigma-Aldrich) for $1 \mathrm{~h}$ at $37^{\circ} \mathrm{C}$. Diaminobenzidine (Sigma-Aldrich) was used as the peroxidase substrate to visualize the positive staining. The nuclei were counterstained using hematoxylin (Sigma-Aldrich). Slides were mounted and observed under a light microscope (Leica DM750; Leica Microsystems GmbH, Wetzlar, Germany). The primary antibody was omitted for negative controls and human colon cancer tissue with strong K-Ras expression was used as a positive control. The slides were examined independently by two pathologists who were blinded to the clinical and pathological data. Immunohistochemical results were quantified based on the extent and intensity of staining. An index value expressed in arbitrary units was calculated to grade the extent and intensity of staining.

Statistical analysis. Statistical significance was evaluated by Student's t-test or one-way analysis of variance followed by the Bonferroni method for multiple comparisons between pairs. Comparison of methylation rates in different tissues were performed using the Fisher's exact test. $\mathrm{P}<0.05$ was considered to indicate a statistically significant difference.

\section{Results}

miR-193b expression is downregulated in human BE and esophageal cancer tissues. The level of miR-193b was examined in human BE tissues, esophageal cancer tissues, and their adjacent, histologically normal tissues. The results demonstrated that $\mathrm{miR}-193 \mathrm{~b}$ expression was significantly downregulated in $\mathrm{BE}$ and esophageal cancer tissues compared with the corresponding normal tissues $(\mathrm{P}=0.002$ and $\mathrm{P}=0.001$, respectively; Fig. 1). Additionally, the expression level of miR-193b in esophageal cancer tissues was significantly reduced compared with the BE tissues $(\mathrm{P}=0.002$; Fig. 1).

Upregulation of miR-193b by hypomethylating agent 5-azacytidine. miR-193b expression levels in a number of $\mathrm{BE}$ and esophageal cancer cell lines were analyzed by RT-qPCR following demethylation by 5-azacytidine treatment. As demonstrated in Fig. 2, demethylation treatment resulted in a significant upregulation of miR-193b in Barrett's esophagus (B-T and B-T10) and esophageal cancer (EC109, SEG-1 and TE-10) cells, with greater increases observed in the esophageal cancer cell lines. By contrast, the level of miR-193b in B-T9 Barrett's esophagus cells and normal esophageal squamous epithelial cells were not observed to be significantly different following exposure to 5-azacytidine (Fig. 2).

miR-193b promoter hypermethylation in human BE and esophageal cancer cells. miR-193b methylation in human BE and esophageal cancer cells was evaluated by MSP analysis. As presented in Fig. 3A, miR-193b was hypermethylated in the $\mathrm{BE}$ and esophageal cancer cell lines. However, normal esophageal squamous epithelial cells exhibited low methylation of the miR-193b promoter region. To confirm the methylation status, cells were treated with 5-azacytidine prior to methylation analysis. The results revealed weak or no methylation of
Table I. Methylation rates of microRNA-193b in human Barrett's esophagus and esophageal cancer tissues.

\begin{tabular}{llll}
\hline Sample & $\mathrm{n}$ & Rate $(\%)$ & P-value \\
\hline Barrett's esophagus & 14 & $37.9 \pm 2.3$ & \\
Adjacent tissue $^{\mathrm{a}}$ & 14 & $28.7 \pm 2.9$ & 0.038 \\
Esophageal cancer $^{\mathrm{A}}$ & 22 & $45.6 \pm 14.4$ & \\
Adjacent tissue $^{\mathrm{b}}$ & 22 & $17.5 \pm 2.9$ & 0.005
\end{tabular}

Normal tissue adjacent to ${ }^{a}$ Barrett's esophagus and besophageal cancer. Values are presented as the mean \pm standard deviation. $\mathrm{P}$-value indicates adjacent tissue vs. tumor tissue.

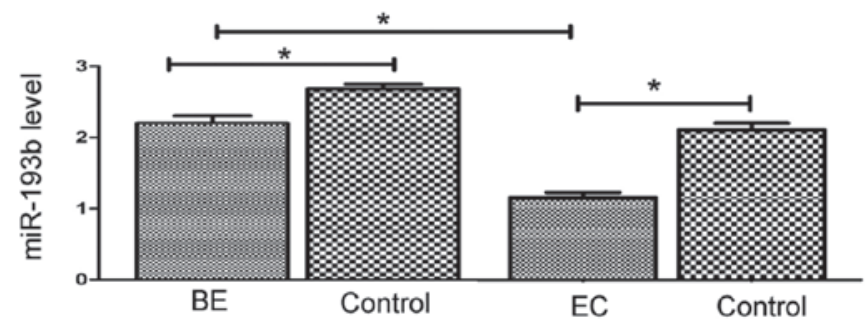

Figure 1. Reverse transcription-quantitative polymerase chain reaction analysis of miR-193b expression in human BE $(n=14), E C(n=22)$ and their adjacent normal tissues. Data are expressed as the mean \pm standard deviation of 3 independent experiments. ${ }^{*} \mathrm{P}<0.05$, comparison indicated by brackets. miR, microRNA; BE, Barrett's esophagus; EC, esophageal cancer.

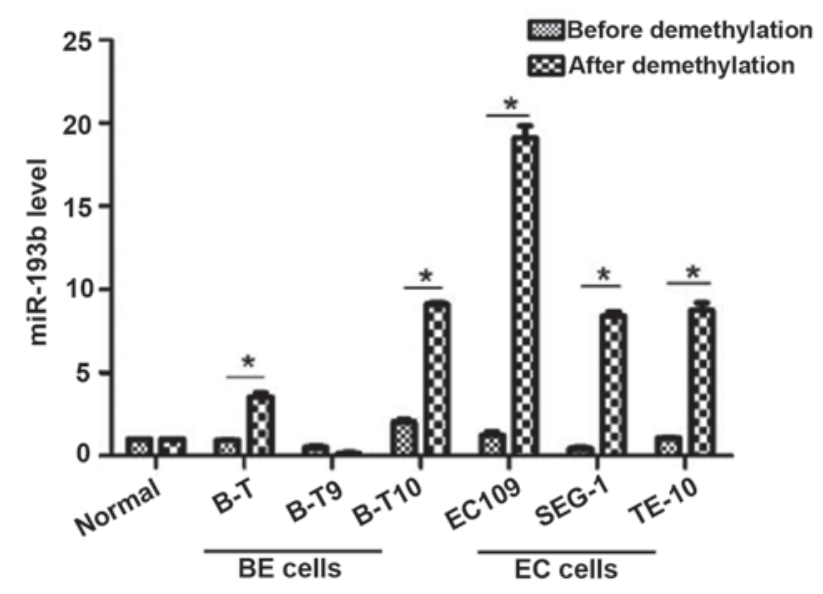

Figure 2. 5-Azacytidine treatment upregulates miR-193b in BE and EC cells. Cells were serum starved for $8 \mathrm{~h}$ and exposed to 5-azacytidine (1\%) for a further $72 \mathrm{~h}$. miR-193b expression was determined using reverse transcription-quantitative polymerase chain reaction analysis. Data are expressed as the mean \pm standard deviation of 3 independent experiments. ${ }^{*} \mathrm{P}<0.05$, comparison indicated by brackets. miR, microRNA; BE, Barrett's esophagus; EC, esophageal cancer.

miR-193b in the 5-azacytidine-treated BE and esophageal cancer cells (Fig. 3B).

miR-193b methylation in human BE and esophageal cancer tissues. Table I presents the methylation rates of miR-193b in human BE and esophageal cancer tissues. miR-193b hypermethylation was detected in $37.9 \pm 2.3 \%$ of BE tissues and in 
Table II. Biological roles of microRNA-193b in human cancer.

\begin{tabular}{|c|c|c|c|c|}
\hline Author, year & Type of cancer & MicroRNA-193b function & Target & Refs. \\
\hline $\begin{array}{l}\text { Chen et al, 2010; } \\
\text { Kaukoniemi et al, } 2015\end{array}$ & Prostate cancer, melanoma & Growth suppression & cyclin D1 & $(17,31)$ \\
\hline $\begin{array}{l}\text { Li et al, } 2009 \\
\text { Mitra } \text { et al, } 2015\end{array}$ & Breast cancer, ovarian cancer & Inhibition of cell invasion & uPA & $(19,32)$ \\
\hline $\mathrm{Xu}$ et al, 2010 & Hepatocellular carcinoma & $\begin{array}{l}\text { Inhibition of proliferation, } \\
\text { migration and invasion }\end{array}$ & cyclin D1, ETS1 & (29) \\
\hline Mets et al, 2015 & T-ALL & Tumor suppression & MYB & $(33)$ \\
\hline $\begin{array}{l}\text { Li et al, 2014; } \\
\text { Jin et al, } 2015\end{array}$ & Pancreatic cancer & $\begin{array}{l}\text { Inhibition of growth and } \\
\text { metastasis }\end{array}$ & $\begin{array}{l}\text { STMN1, uPA, } \\
\text { K-Ras }\end{array}$ & $(28,34)$ \\
\hline Lenarduzzi et al, 2013 & HNSCC & Acceleration of tumor progression & Neurofibromin 1 & $(30)$ \\
\hline Zhong et al, 2014 & Glioma & Promotion of cell proliferation & Smad3 & $(35)$ \\
\hline
\end{tabular}

T-ALL, T-cell acute lymphoblastic leukemia; HNSCC, head and neck squamous cell carcinoma; uPA, urokinase-type plasminogen activator; ETS1, v-ets avian erythroblastosis virus E26 oncogene homolog 1; MYB, v-myb avian myeloblastosis viral oncogene homolog; STMN1, stathmin 1; K-Ras, Kirsten rat sarcoma viral oncogene homolog; Smad3, Smad family member 3.
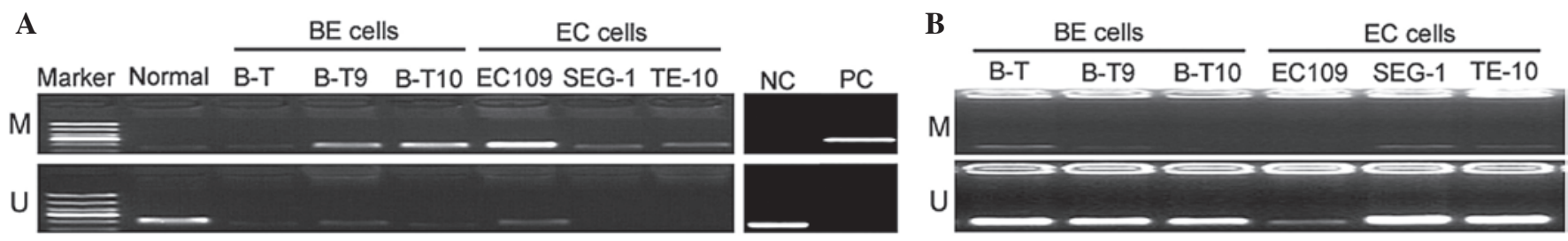

Figure 3. MSP analysis of miR-193 promoter methylation status. BE and EC cells were incubated in the (A) absence or (B) presence of 5-azacytidine for $72 \mathrm{~h}$ and subsequently subjected to MSP analysis. Representative gels of MSP products from three independent experiments are presented. MSP, methylation-specific polymerase chain reaction; miR, microRNA; BE, Barrett's esophagus; EC, esophageal cancer; NC, negative control; PC, positive control; M, methylated; U, unmethylated.
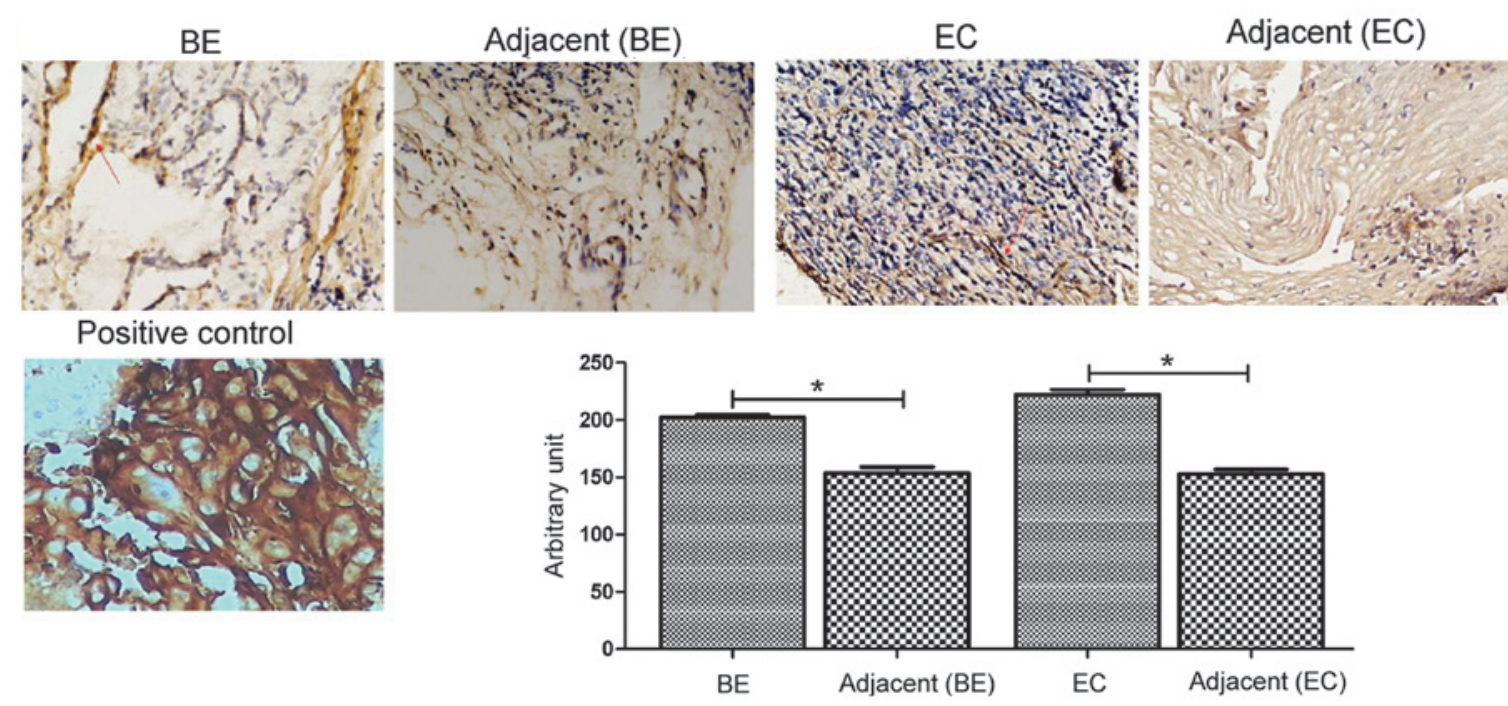

Figure 4. Immunohistochemical analysis of Kirsten rat sarcoma viral oncogene homolog expression in EC and BE tissues and their adjacent normal tissues. Representative images (x100) are presented. Bar graph represents quantification of the immunohistochemical results expressed as arbitrary units. ${ }^{*} \mathrm{P}<0.05$, comparison indicated by brackets. BE, Barrett's esophagus; EC, esophageal cancer.

$45.6 \pm 14.4 \%$ of esophageal cancer tissues. The methylation rates in $\mathrm{BE}$ and esophageal cancer tissues were significantly increased compared with the corresponding adjacent normal esophageal tissues ( $\mathrm{P}=0.038$ and $\mathrm{P}=0.005$, respectively).
$K$-Ras protein expression in human BE and esophageal cancer tissues. K-Ras was previously identified as a direct target of miR-193b in epidermal squamous cell carcinoma (22). The current study investigated the expression of K-Ras protein in 
esophageal cancer. Immunohistochemistry demonstrated that human BE and esophageal cancer tissues exhibited stronger $\mathrm{K}$-Ras protein levels than the corresponding adjacent normal tissues ( $\mathrm{P}=0.005$ and $\mathrm{P}=0.001$, respectively; Fig. 4).

\section{Discussion}

Dysregulation of miRNAs is an important mechanism of tumorigenesis (10), and various miRNAs have been identified to be aberrantly expressed in esophageal cancer (23). The data of the present study demonstrated that miR-193b was weakly expressed in esophageal cancer tissues compared with adjacent normal tissues. Additionally, the expression level of miR-193b in esophageal cancer was significantly decreased compared with the level in BE tissues. In agreement with the findings of the current study, previous investigations have reported the downregulation of miR-193b in several other malignancies $(19,24,25)$. For example, Gao et al (24) reported that miR-193b acts as a tumor suppressor gene, and is downregulated in acute myeloid leukemia (AML). Using miRNA microarray technology, Wu et al (25) profiled the miRNA expression in endometrioid adenocarcinoma and observed that miR-193b was downregulated in adenocarcinoma tissues compared with adjacent non-tumorous endometrium. BE is a premalignant lesion that predisposes patients to EAC (4). The downregulation of miR-193b may contribute to the progression from BE to EAC.

Epigenetic modification of promoter regions, particularly DNA methylation, is frequently associated with the downregulation of genes (26). Epigenetic regulation of miRNA expression commonly occurs in cancer (14). Rauhala et al (18) reported that miR-193b DNA is methylated in prostate cancer cells at a $\mathrm{CpG}$ island $\sim 1 \mathrm{~kb}$ upstream of the miRNA locus. Methylation-mediated silencing of miR-193b has also been described in dedifferentiated liposarcoma cells (27).

The current study demonstrated that miR-193b was hypermethylated in esophageal cancer tissues and cells at its promoter region. Aberrant methylation of the miR-193b promoter occurred less frequently in BE tissues. By contrast, normal esophageal squamous epithelial cells exhibited low methylation of miR-193b compared with the BE and cancer cells. To confirm the methylation status of miR-193b, the present study used the hypomethylating agent 5 -azacytidine to treat esophageal cancer and BE cells, and examined the expression levels of miR-193b. Treatment with 5-azacytidine resulted in a significant increase of miR-193b expression compared with untreated cells. To the best of our knowledge, these results provide the first evidence for DNA methylation-mediated downregulation of miR-193b in BE and esophageal cancer tissues.

The reduced expression levels of miR-193b in BE and esophageal cancer tissues suggest that it negatively regulates the pathogenesis of esophageal cancer. Indeed, miR-193b has been previously demonstrated to act as a tumor suppressor gene in several types of human cancer, including melanoma (17), AML (24), pancreatic cancer (28) and hepatocellular carcinoma (29). However, miR-193b has been demonstrated to enhance tumor progression in head and neck squamous cell carcinoma (HNSCC) cells (30). Overexpression of miR-193b occurs in HNSCC cells, and knockdown of its expression has been demonstrated to result in reduced cell proliferation, migration, invasion and tumorigenesis (30). Table II summarizes the biological roles of miR-193b in human cancer. Additional direct evidence is required to confirm the exact biological functions of miR-193b in esophageal cancer.

A single miRNA can modulate hundreds of target genes (36), and several targets of miR-193b have been identified. Zhong et al (35) reported that miR-193b is capable of accelerating human glioma cell proliferation via targeting Smad family member 3 . Neurofibromin 1 (NF1) is also a target of miR-193b, and downregulation of NF1 promotes the HNSCC aggressiveness induced by miR-193b (30). Gastaldi et al (22) identified K-Ras as a direct target of miR-193b. Activation of the K-Ras oncogene has been implicated in tumorigenesis (37). The data of the present study demonstrated that human BE and esophageal cancer tissues exhibited increased expression of K-Ras protein compared with adjacent normal tissues. The upregulation of K-Ras in BE and esophageal cancer tissues may be the result of the epigenetic silencing of miR-193b.

A number of limitations of the present study should be noted. The importance of miR-193b in the development and progression of EC remain unclear. Additionally, it remains to be determined whether the action of miR-193b in esophageal cancer is mediated by targeting K-Ras. No information is available on the action of miR-193b in xenograft in vivo models.

In conclusion, to the best of our knowledge, this is the first report investigating epigenetic silencing of miR-193b via DNA methylation in esophageal cancer and $B E$ tissues. Downregulation of miR-193b and upregulation of K-Ras may contribute to the pathogenesis of esophageal cancer. The clinical and biological relevance of miR-193b is unclear and requires further exploration.

\section{Acknowledgements}

The current work was supported by the National Natural Science Foundation of China (no. 81101827) and the Key Program of Bureau of Health of Chongqing of China (no. 20111055).

\section{References}

1. Jemal A, Bray F, Center MM, Ferlay J, Ward E and Forman D: Global cancer statistics. CA Cancer J Clin 61: 69-90, 2011.

2. Napier KJ, Scheerer M, and Misra S: Esophageal cancer: A review of epidemiology, pathogenesis, staging workup and treatment modalities. World J Gastrointest Oncol 6: 112-120, 2014.

3. Brown LM, Devesa SS and Chow WH: Incidence of adenocarcinoma of the esophagus among white americans by sex, stage, and age. J Natl Cancer Inst 100: 1184-1187, 2008.

4. Shaheen NJ and Richter JE: Barrett's oesophagus. Lancet 373: 850-861, 2009.

5. Hvid-Jensen F, Pedersen L, Drewes AM, Sørensen HT and Funch-Jensen P: Incidence of adenocarcinoma among patients with Barrett's esophagus. N Engl J Med 365: 1375-1383, 2011.

6. Cameron AJ and Lomboy CT: Barrett's esophagus: Age, prevalence, and extent of columnar epithelium. Gastroenterology 103: 1241-1245, 1992

7. Wild CP and Hardie LJ: Reflux, Barrett's oesophagus and adenocarcinoma: Burning questions. Nat Rev Cancer 3: 676-684, 2003.

8. Ke XS, Liu CM, Liu DP and Liang CC: MicroRNAs: Key participants in gene regulatory networks. Curr Opin Chem Biol 7: 516-523, 2003.

9. Nilsen TW: Mechanisms of microRNA-mediated gene regulation in animal cells. Trends Genet 23: 243-249, 2007. 
10. Melo SA and Esteller M: Dysregulation of microRNAs in cancer: Playing with fire. FEBS Lett 585: 2087-2099, 2011.

11. Fassan M, Baffa R, Kiss A, Zaninotto G and Rugge M: MicroRNA dysregulation in esophageal neoplasia: The biological rationale for novel therapeutic options. Curr Pharm Des 19: 1236-1241, 2013.

12. Zhang B, Pan X, Cobb GP and Anderson TA: MicroRNAs as oncogenes and tumor suppressors. Dev Biol 302: 1-12, 2007.

13. Hayes J, Peruzzi PP, and Lawler S: MicroRNAs in cancer: Biomarkers, functions and therapy. Trends Mol Med 20: 460-469, 2014.

14. Suzuki H, Maruyama R, Yamamoto E and Kai M: DNA methylation and microRNA dysregulation in cancer. Mol Oncol 6: 567-578, 2012.

15. Li X, Lin R and Li J: Epigenetic silencing of microRNA-375 regulates PDK1 expression in esophageal cancer. Dig Dis Sci 56: 2849-2856, 2011.

16. Cui X, Zhao Z, Liu D, Guo T, Li S, Hu J, Liu C, Yang L, Cao Y, Jiang J, et al: Inactivation of miR-34a by aberrant CpG methylation in Kazakh patients with esophageal carcinoma. J Exp Clin Cancer Res 33: 20, 2014.

17. Chen J, Feilotter HE, Paré GC, Zhang X, Pemberton JG, Garady C, Lai D, Yang X and Tron VA: MicroRNA-193b represses cell proliferation and regulates cyclin D1 in melanoma. Am J Pathol 176: 2520-2529, 2010

18. Rauhala HE, Jalava SE, Isotalo J, Bracken $H$, Lehmusvaara $S$, Tammela TL, Oja H and Visakorpi T: miR-193b is an epigenetically regulated putative tumor suppressor in prostate cancer. Int J Cancer 127: 1363-1372, 2010.

19. Li XF, Yan PJ and Shao ZM: Downregulation of miR-193b contributes to enhance urokinase-type plasminogen activator (uPA) expression and tumor progression and invasion in human breast cancer. Oncogene 28: 3937-3934, 2009.

20. Livak KJ and Schmittgen TD: Analysis of relative gene expression data using real-time quantitative PCR and the 2(- $\Delta \Delta \mathrm{C}(\mathrm{t}))$ method Methods 25: 402-408, 2001.

21. Huang YW, Kuo CT, Chen JH, Goodfellow PJ, Huang TH, Rader JS and Uyar DS: Hypermethylation of miR-203 in endometrial carcinomas. Gynecol Oncol 133: 340-345, 2014.

22. Gastaldi C, Bertero T, Xu N, Bourget-Ponzio I, Lebrigand $\mathrm{K}$ Fourre S,Popa A, Cardot-Leccia N, Meneguzzi G, Sonkoly E, et al miR-193b/365a cluster controls progression of epidermal squamous cell carcinoma. Carcinogenesis 35: 1110-1120, 2014.

23. Zang W, Wang Y, Du Y, Xuan X, Wang T, Li M, Ma Y, Li P, Chen X, Dong Z and Zhao G: Differential expression profiling of microRNAs and their potential involvement in esophageal squamous cell carcinoma. Tumour Biol 35: 3295-3304, 2014.

24. Gao XN,Lin J, Gao L, Li YH, Wang LL and Yu L: MicroRNA-193b regulates c-Kit proto-oncogene and represses cell proliferation in acute myeloid leukemia. Leuk Res 35: 1226-1232, 2011.
25. Wu W, Lin Z, Zhuang Z and Liang X: Expression profile of mammalian microRNAs in endometrioid adenocarcinoma. Eur J Cancer Prev 18: 50-55, 2009.

26. Issa JP: CpG island methylator phenotype in cancer. Nat Rev Cancer 4: 988-993, 2004.

27. Taylor BS, DeCarolis PL, Angeles CV, Brenet F, Schultz N, Antonescu CR, Scandura JM, Sander C, Viale AJ, Socci ND and Singer S: Frequent alterations and epigenetic silencing of differentiation pathway genes in structurally rearranged liposarcomas. Cancer Discov 1: 587-597, 2011.

28. Li J, Kong F, Wu K, Song K, He J and Sun W: miR-193b directly targets STMN1 and uPA genes and suppresses tumor growth and metastasis in pancreatic cancer. Mol Med Rep 10: 2613-2620, 2014.

29. Xu C, Liu S, Fu H, Li S, Tie Y, Zhu J, Xing R, Jin Y, Sun Z and Zheng X: MicroRNA-193b regulates proliferation, migration and invasion in human hepatocellular carcinoma cells. Eur J Cancer 46: 2828-2836, 2010.

30. Lenarduzzi M, Hui AB, Alajez NM, Shi W, Williams J, Yue S, O'Sullivan B and Liu FF: MicroRNA-193b enhances tumor progression via down regulation of neurofibromin 1 . PLoS One 8: e53765, 2013.

31. Kaukoniemi KM, Rauhala HE, Scaravilli M, Latonen L, Annala M, Vessella RL, Nykter M, Tammela TL and Visakorpi T: Epigenetically altered miR-193b targets cyclin D1 in prostate cancer. Cancer Med 4: 1417-1425, 2015.

32. Mitra AK, Chiang CY, Tiwari P, Tomar S, Watters KM, Peter ME and Lengyel E: Microenvironment-induced downregulation of miR-193b drives ovarian cancer metastasis. Oncogene 34: 5923-5932, 2015

33. Mets E, Van der Meulen J, Van Peer G, Boice M, Mestdagh P, Van de Walle I, Lammens T, Goossens S, De Moerloose B, Benoit Y, et al: MicroRNA-193b-3p acts as a tumor suppressor by targeting the MYB oncogene in T-cell acute lymphoblastic leukemia. Leukemia 29: 798-806, 2015.

34. Jin X, Sun Y, Yang H, Li J, Yu S, Chang X, Lu Z and Chen J: Deregulation of the MiR-193b-KRAS Axis Contributes to Impaired Cell Growth in Pancreatic Cancer. PLoS One 10: e0125515, 2015.

35. Zhong Q, Wang T, Lu P, Zhang R, Zou J and Yuan S: miR-193b promotes cell proliferation by targeting $\mathrm{Smad} 3$ in human glioma. J Neurosci Res 92: 619-626, 2014.

36. Satoh J: Molecular network of microRNA targets in Alzheimer's disease brains. Exp Neurol 235: 436-446, 2012.

37. Brink M, de Goeij AF, Weijenberg MP, Roemen GM, Lentjes MH, Pachen MM, Smits KM, de Bruïne AP, Goldbohm RA and van den Brandt PA: K-ras oncogene mutations in sporadic colorectal cancer in The Netherlands Cohort Study. Carcinogenesis 24: 703-710, 2003. 